\title{
A hospital based cross sectional study to evaluate awareness of lifestyle interventions among hypertensive patients in Sikkim (North-Eastern State of India)
}

\author{
Dhakal M. ${ }^{1}$, Dhakal O.P. ${ }^{2}$ \\ ${ }^{1}$ Dr. Mona Dhakal, Professor, ${ }^{2}$ Dr. O.P. Dhakal, Professor, both authors are attached with Department of Medicine, \\ Sikkim Manipal Institute of Medical Sciences, 5th Mile, Gangtok Sikkim, India
}

Address for Correspondence: Dr. O P Dhakal, Professor of Medicine, Sikkim Manipal Institute of Medical Sciences, 5th Mile, Gangtok Sikkim

\begin{abstract}
Introduction: Hypertension (HTN) or high blood pressure (BP) is the most important cardiovascular risk factor worldwide, contributing to around one half of the coronary heart disease and two thirds of the cerebrovascular disease burdens. Effective prevention, detection, treatment, and control of BP continue to be an important goal for health care providers. A positive impact of life-style interventions is a well known fact. Awareness of HTN remains an important concern in this mountainous and predominantly rural population. Objective: To evaluate the awareness of lifestyle interventions among patients of hypertension. Methods: A cross-sectional study was conducted in Sikkim Manipal Institute of Medical Sciences in general medicine OPD from Jan 1. 2017 to Jan 15, 2017. All the stable hypertensive patients, attending medicine OPD aged $>18$ years were recruited in the study. Patients were interviewed using a semi structured questionnaire regarding knowledge of life style interventions. Results: Among all the hypertensive patients $(n=100), 60$ patients had adequate knowledge $(>50 \%)$ and 40 patients had inadequate $(<50 \%)$ knowledge of these interventions. Significant association between educational background and knowledge on lifestyle interventions was present. Urban population was more aware as compared to rural population Blood pressure was significantly under control in the aware population. Conclusion: Patients knowledge on lifestyle interventions for the management of blood pressure is important. The rural population and uneducated people have inadequate knowledge on lifestyle modifications of hypertension. Structured teaching programs are needed to improve awareness about the lifestyle changes.
\end{abstract}

\section{Introduction}

Hypertension imposes a substantial public health burden on cardiovascular health status and healthcare systems in India [1]. It is responsible for more than half of all stroke deaths and approximately a quarter of all coronary heart disease deaths in India [2]. Recent studies from India have shown the prevalence of HTN to be $25 \%$ in urban and $10 \%$ in rural people [3]. In the year 2000, the combined urban and rural prevalence was $20.6 \%$ among males and $20.9 \%$ among females and in 2025 the projected rate will be $22.9 \%$ among males and $23.6 \%$ among females [4]. Awareness and control of HTN in India ranged from 20 to $54 \%$ and 7.5 to $25 \%$, respectively in a Meta analysis of various studies [5]. Very few studies related to prevalence and awareness of hypertension in Sikkim is found in the literature. A study carried out among the Lepchas of Sikkim Himalayas has documented hypertension prevalence of $30.77 \%$ among males and $25.77 \%$ among females [6]. This is rather more as compared to rest of India.

According to a multicenter study from India on awareness, treatment, and adequacy of control of HTN, only about $25.6 \%$ of treated patients had their BP under control [7]. There is evidence that life style modifications and adequate control of

Manuscript received: $01^{\text {st }}$ April 2017

Reviewed: $12^{\text {th }}$ April 2017

Author Corrected: 20 ${ }^{\text {th }}$ April 2017

Accepted for Publication: $30^{\text {th }}$ April 2017 
blood pressure with medicines can help manage hypertension effectively and prevent complications such as stroke [8]. Inadequate control of blood pressure may be related to patient barriers such as lack of knowledge on hypertension and its treatment, cultural beliefs, access to care, high cost of medicines and discontinuation of medicines as a result of side effects [9]. Insufficient knowledge of hypertensive patients about the administration of their medication and life style modifications could lead to low control of their blood pressure [10]. This has been reported among hypertensive patients both in the developed and developing countries [11]. The highest perceived barrier of life style modification practices related to hypertension is lack of knowledge in India also [12].

Recommended life style interventions and their effect on blood pressure [13].

\begin{tabular}{|c|c|c|}
\hline Non Pharmalogical Measures & Recommendations & $\begin{array}{c}\text { Estimated Systolic BP reduction } \\
\text { ( } \mathrm{mm} \mathrm{Hg})\end{array}$ \\
\hline Body weight reduction & $\begin{array}{l}\text { Attain a normal body weight with a } \\
\text { BMI ranging from } 18.5 \text { to } 24.9 \mathrm{~kg} / \mathrm{m} 2\end{array}$ & $\begin{array}{l}\text { A } 10 \mathrm{~kg} \text { loss in body weight } \\
\text { attenuates BP by } 5-20 \mathrm{mmHg}\end{array}$ \\
\hline DASH type dietary pattern & $\begin{array}{l}\text { Intake of vegetables, fruits and milk } \\
\text { products with low saturated and low } \\
\text { total fat. }\end{array}$ & $\begin{array}{l}\text { Alteration in dietary habits lowers } \\
\text { BP by } 8-14 \mathrm{mmhg} \text {. }\end{array}$ \\
\hline Cut salt & $\begin{array}{l}\text { Cutting down salt intake to the fullest } \\
\text { extent possible } \\
\text { Optimal level: } 1.5 \mathrm{~g} / \text { day sodium or } \\
3.8 \mathrm{~g} / \text { day sodium chloride }\end{array}$ & $\begin{array}{l}\text { Reduce salt intake cuts BP by } 2- \\
\qquad 8 \mathrm{mmHg}\end{array}$ \\
\hline Exercise & $\begin{array}{c}\text { Regular aerobic physical activity for } \\
\text { about } 30 \mathrm{~min} / \text { day maximum days of the } \\
\text { week }\end{array}$ & Attenuates BP by $4-9 \mathrm{mmhg}$ \\
\hline Alcohol intake & $\begin{array}{c}\text { Maximum } 2 \text { drinks/day for men and } 1 \\
\text { drink/day for women and light weight } \\
\text { persons }\end{array}$ & $\begin{array}{l}\text { Lowering alcohol intake lowers the } \\
\text { BP by } 2-4 \text { mmhg. }\end{array}$ \\
\hline
\end{tabular}

Sikkim is a tiny hilly state in north-east India. According to 2011 census, $74.85 \%$ of total population lives in rural area and only $25.15 \%$ lives in urban area. Young mountains with difficult terrain characterizes it geography. The state has adult literacy rate around $82.2 \%$ according to the census 2011. Average literacy rate in Sikkim for rural areas was $78.95 \%$ slightly less as compared to urban areas. There is a significant difference in the rural and urban areas of India for awareness and control of HTN [2]. At the same time, eastern India had the highest prevalence of hypertension equaling the prevalence seen in urban parts of India. Rural parts of India have lower literacy rates and have wider disparity in access and quality of health services as compared with urban areas [2]. So, the awareness of HTN remains an important concern in this predominantly rural population.

\section{Materials and Method}

Study design and setting- This prospective cross sectional was carried out in a tertiary care hospital, Sikkim Manipal Institute of Medical Sciences in a period of 15 days between Jan 1, 2017 to Jan 15, 2017.

Inclusion Criteria- included adult patients $>18$ years of age, attending medicine OPD and having hypertension for more than six months with no co-morbidities.

Exclusion criteria- Patients having acute problems and those did not give consent were excluded from the study.
Study size- A total of 100 hypertensive patients, including 62males and 36 females who fulfilled the inclusion criteria, were selected. Purposive sampling method was used to select the hypertensive patients.

Procedure and methods of data collection- Ethical clearance was sought from the institutional ethical committee before data was collected .Face to face interviews was conducted after the patients oral consent has been sought. Purposive sampling method was used to select the hypertensive patients. 
The semi structured questionnaire captured the following: socio- demographic and clinical characters, duration of hypertension and intake of anti-hypertensive drugs. In addition knowledge and performance on 6 lifestyle modification which included aerobic exercise at least 30 minutes per day, four days per week, reducing dietary salt to less than $6 \mathrm{~g} \mathrm{NaCl}$ per day, limiting alcohol intake to less than 3 units per day for men and less than 2 units day for women, avoiding cigarette smoking, maintaining healthy weight and eating a diet high in fruits, nuts and vegetable and low in fat was gathered. The data were collected in the private room by two researchers, knowledge and perceptions sheet toward lifestyle behavior modifications were distributed to the attending hypertensive patients.

Each of them was asked to complete assessment sheets and return them to the researchers in the same visit. In the case of patients were illiterate, the sheets were filled by the researchers through in-depth interview by reading each question to the patients and take answer from them.

\begin{abstract}
Measurements and calculation-To determine respondent's knowledge on the life style modification for managing hypertension, a scoring system was employed where patients were given a score on each life style modification known, and the patients were divided as having $<50 \%$ knowledge(knowledge of $<3$ interventions) or equal to or $>50 \%$ knowledge (knowledge of $\geq 3$ interventions) about those. Those patients having $<50 \%$ knowledge were considered to have inadequate and equal to or $>50 \%$ knowledge were considered to have inadequate knowledge. BMI and waist circumference was noted to check maintenance of healthy weight. Three blood pressure measurements were obtained by use of standardized mercury sphygmomanometer after a 5-minute sitting rest. B.P. was considered high if average systolic blood pressure $\geq 140 \mathrm{~mm} \mathrm{Hg}$, diastolic blood pressure $\geq 90 \mathrm{~mm} \mathrm{Hg}$.
\end{abstract}

Data analysis was done using SPSS version 15 . Fisher exact test was used to test the association between the variables and a $p$ value of $\leq 0.5$ was considered indicative of statistically significant difference. The likelihood of occurrence of events was tested by odds ratio at $95 \%$ confidence level.

\section{Results}

Among all the hypertensive patients examined in the study $(n=100), 62$ were females and 38 were males. 92 patients were receiving pharmacotherapy, and only 32 patients had their blood pressure adequately controlled. 20 females and 12 males had BP under control and the difference was statistically insignificant [P=0.94, OR 1.03, CI 95 \%( 90.43-2.45)]. Out of those patients with adequate knowledge $(\mathrm{N}=60), 30$ patients follow all the interventions, 16 followed some and 14 did not follow any despite having knowledge of different methods of the same. 40 patients had $<50 \%$ knowledge of those interventions. Among life style interventions in patients with adequate knowledge, awareness regarding salt restriction was highest, present in 42 patients followed by regular exercise in 35 patients, abstinence from smoking in 32 , and regarding DASH eating plan; it was lowest, present only in 30 patients. 6 patients consumed alcohol routinely. In aware but non followers, 6 were smokers and 2 consumed alcohol regularly.

In patients with inadequate knowledge $(\mathrm{N}=40), 11$ patients had knowledge regarding salt restricted diet, 5 and 7 patients were aware of abstinence from smoking and regular exercise respectively. None of these patients had knowledge of DASH eating plan. 12 patients were smokers and 24 patients used to consume alcohol routinely.

20 were vegetarian in adequately aware population as compared to 6 in inadequately aware one.

52 were uneducated or had only basic education out of total 100 (62 females and 38 males) patients. 26 patients out of 60 patients and 26 patients out of 40 patients had only basic education or were uneducated. Effect of gender on patients knowledge on life style modification for the management of hypertension was insignificant $[\mathrm{P}=0.74, \mathrm{OR} 0.87,95 \% \mathrm{CI}$ $(0.38-1.97)]$ and for educational background it was significant $[\mathrm{P}=0.04$, OR $0.41,95 \% \mathrm{CI}(0.18-0.94)]$. Urban to rural ratio was 54:6 as opposed to 20:20 in unaware group. Urban population was more aware as compared to rural population $[\mathrm{P}=<.0001$, OR 9, 95\% CI (3.12-25.63). Blood pressure was significantly under control in the population having adequate knowledge $[\mathrm{P}=0.04$, OR 2.6, 95\% CI (1.05-6.77)]. Difference in BMI was insignificant among both the groups $[\mathrm{P}=0.72$, OR1.17, 95\%CI (0.49-2.86)]. Similarly, it was insignificant for smoking/tobacco consumption or alcohol intake $(\mathrm{P}=1$ and 0.142 respectively). 
Table-1: Distribution of studied hypertensive population according to their socio demographic profile $(\mathrm{N}=100)$

\begin{tabular}{|c|c|c|c|c|c|}
\hline Variable & $\begin{array}{c}\text { Number } \\
\mathrm{N}=100\end{array}$ & $\begin{array}{c}\text { Patients with } \\
\text { adequate } \\
\text { knowledge }\end{array}$ & $\begin{array}{c}\text { Patients with } \\
\text { inadequate } \\
\text { knowledge }\end{array}$ & $P$ value & OR $95 \%$ CI \\
\hline \multicolumn{6}{|l|}{ Age } \\
\hline $20-40$ & 18 & 10 & 8 & \multirow{3}{*}{0.14} & \\
\hline $41-60$ & 54 & 20 & 34 & & \\
\hline $61-80$ & 28 & 16 & 12 & & \\
\hline \multicolumn{6}{|l|}{ Gender } \\
\hline Male & 38 & 22 & 16 & \multirow[t]{2}{*}{0.74} & \multirow[t]{2}{*}{$0.86(0.38-1.97)$} \\
\hline Female & 62 & 38 & 24 & & \\
\hline \multicolumn{6}{|l|}{ Educational level } \\
\hline Uneducated or Basic & 48 & 26 & 26 & \multirow[t]{2}{*}{0.04} & \multirow[t]{2}{*}{$0.41(0.18-0.94)$} \\
\hline Educated & 52 & 34 & 14 & & \\
\hline \multicolumn{6}{|l|}{ Marital status } \\
\hline Married & 96 & 59 & 37 & \multirow[t]{2}{*}{0.18} & \multirow[t]{2}{*}{$4.78(0.48-47.72)$} \\
\hline Unmarried & 4 & 1 & 3 & & \\
\hline$<140 / 90$ & 32 & 24 & 8 & \multirow[t]{2}{*}{0.04} & \multirow[t]{2}{*}{$2.69(1.05-6.77)$} \\
\hline$>140 / 90$ & 68 & 36 & 32 & & \\
\hline Smokers & 14 & 8 & 6 & 0.81 & $0.87(0.28-2.73)$ \\
\hline Alcohol use & 22 & 10 & 12 & 0.12 & $0.47(0.18-1.21)$ \\
\hline \multicolumn{6}{|l|}{ BMI } \\
\hline$<24.9$ & 28 & 16 & 12 & \multirow[t]{2}{*}{0.72} & \multirow[t]{2}{*}{$1.17(0.49-2.86)$} \\
\hline$>25$ & 72 & 44 & 28 & & \\
\hline \multicolumn{6}{|l|}{ Location } \\
\hline Urban & 74 & 54 & 20 & $<.0001$ & $9(3.12-25.63)$. \\
\hline Rural & 26 & 6 & 20 & & \\
\hline
\end{tabular}

Table-2: Knowledge on life style modifications in studied population.

\begin{tabular}{|c|c|}
\hline Intervention & Number of patients with knowledge(N=100) \\
\hline $\begin{array}{c}\text { 1. Reducing dietary salt to less than } 2.4 \mathrm{~g} \text { per day } \\
\text { 2. Aerobic exercise at least 30 minutes per day, } \\
\text { four days per week. }\end{array}$ & 43 \\
\hline 3. Avoiding cigarette smoking & 37 \\
\hline 4. Limiting alcohol intake & 32 \\
\hline 5. Maintaining a healthy weight & 32 \\
\hline $\begin{array}{c}\text { 6. Eating a diet high in fruits, nuts, vegetables } \\
\text { and low in fat }\end{array}$ & 30 \\
\hline
\end{tabular}

Table-3: Practice of life style interventions among patients having adequate knowledge $(\mathrm{N}=60)$

\begin{tabular}{|c|c|}
\hline Patients & Number \\
\hline Aware and follow all & $30(50 \%)$ \\
\hline Aware and follow some & $16(27 \%)$ \\
\hline Aware but do not follow & $14(23 \%)$ \\
\hline
\end{tabular}




\section{Discussion}

Hypertension is one of the most common chronic health conditions and a leading cause of mortality and morbidity [14]. Control of hypertension by lifestyle modifications can decrease the cost of health care by decreasing the use of pharmacological and invasive cardiovascular treatments $[15,16]$. The study was conducted to assess the level of knowledge relating to lifestyle modifications. In socio-demographic characteristics of the hypertensive patients, the study revealed that the majority of the patients $(54 \%)$ were in 41-60 years old. This was consistent with the finding of few studies [17, 18] where, a high prevalence of hypertension was found among older adults. There were more females. This may be due to the effect of postmenopausal hormones deficiency and some risk factors as obesity, stressful situation and it was similar to a study [19]. As regard to knowledge about lifestyle behavior modifications, the study results revealed that more than half of the patients had fair to good /adequate knowledge about lifestyle behavior modifications (Table 1). A similar study revealed that more than half of hypertensive patients were aware of the family history, smoking and excessive salt intake increased risk of hypertension [20]. This was in contrast with the study where knowledge of the participants about lifestyle modifications such as activity and exercises to control hypertension was poor [21]. Similarly, another study revealed that more than half of the patients were had fair knowledge, $23.8 \%$ from them were had poor knowledge and only $8.9 \%$ from them were had good knowledge about lifestyle behavior modifications [22]. In our study, 40 patients had inadequate knowledge regarding life style changes. This also in the similar to a study [23] which reported that up to $80 \%$ from hypertensive subjects were not aware about the role of various lifestyle modifications such as DASH eating plan and maintenance of healthy body weight.

Among life style interventions in patients with adequate knowledge, awareness regarding salt restriction was highest followed by regular exercise and abstinence from smoking whereas regarding DASH eating plan, it was lowest in our study.6 patients consumed alcohol routine. This was similar with a study which found that the excessive salt intake as a risk factor for hypertension was a most known risk factor $(77.4 \%)$, though in that study the least awareness was regarding moderation of alcohol consumption (47.6\%) [24]. On the other hand, another study revealed that more than $70 \%$ of patients were aware that stress, high cholesterol and obesity were the risk factors of hypertension and $52.7 \%$ from them were not aware that the lack of physical activity was risk factors for hypertension [25]. One more study reported that the awareness regarding stress, excessive salt intake and obesity is good but poor awareness regarding excessive alcohol intake, smoking and a sedentary lifestyle [26]. Awareness of DASH eating diet was least in our study. At the same time, importance of maintaining healthy weight in controlling hypertension is also not known to many patients. It was similar to a study [23]. One study had shown that the Sixty percent $60 \%, 62 \%$ and $59 \%$ of respondents were aware of lifestyle modification such as regular exercise; reduce salt intake and eating a diet high in fruits, vegetables and low in fat respectively. In addition 38\% were aware of avoidance of cigarette smoking and $46 \%$ were aware of reduction in alcohol intake [27].

In the United State a study conducted indicated that of hypertensive patients interviewed $78 \%$ of patient's reported receiving advice on regular Exercise, 69.3\% were aware of reducing salt intake, $61.9 \%$ were aware eating habits and $43.5 \%$ were aware of advice on reduced alcohol intake[28].

Thirty percent $(30 \%)$ of hypertensive patients interviewed in South Africa reported that they received advice on the benefits of exercise, $69 \%$ were advised on reduced salt intake and $50 \%$ on a balanced diet. Forty four (44\%) of respondents were advised on reduced alcohol intake and $35 \%$ were advised on cigarette smoke cessation [29].This studies suggest that counseling or advise on each of these interventions should be provided by health care providers to ensure sufficient awareness and adherence to these interventions. Our patients were less familiar with are DASH eating diet and maintenance of healthy weight. Probably counseling on these life style interventions was not provided to those patients also.

Adequately aware population does not practice those interventions despite having knowledge of the same. (Table3)This was similar to a study which showed that $80 \%$ of the hypertensive patients knew that they should limit their salt intake but only one third always avoided salty foods [30]. This was also seen in a study where $(60 \%)$ respondents were aware of regular aerobic exercise however only $40 \%$ where practicing it. $62 \%$ of respondents were aware of the practice of reducing salt intake but only $42 \%$ were actually practicing this . With 
regard to the practice of avoidance of cigarettes smoking; although $36 \%$ of respondents were aware, $20 \%$ of them were smokers [27].

Significant association between educational background and knowledge on lifestyle interventions was present. One study conducted in china has shown that about $77.3 \%$ of hypertensive patients were illiterate. Illiterate patients had difficulty in accepting hypertension knowledge [31]. According to one study, most of the hypertensive patients had no information at all about disease due to insufficient educational sources[33]. This could be one of the reasons of lack of awareness in our study also. Another study revealed that most of the subjects were not aware about life style interventions probably due to poor educational level [22].

We found that urban population is more aware of the interventions than rural population as they are more exposed to educational resources and have good access to health care facilities. This result was consistent with a meta analysis of a study [2].

\section{Conclusion}

Awareness as well as practice of lifestyle interventions is important in management of hypertension. Proper counseling about all the risk factors and interventions should be provided by health care providers especially in rural areas with more elderly population and poor health care facilities.

\section{Funding: Nil, Conflict of interest: None Permission of IRB: Yes}

\section{References}

1. Raghupathy Anchala, Nanda K Kannuri, Hira Pant, Oscar H. Franco et al. Hypertension in India: a systematic review and meta-analysis of prevalence, awareness, and control of hypertension. J Hypertens. $2014 \quad$ Jun; 32(6): 1170-1177. doi: $10.1097 / \mathrm{HJH} .0000000000000146$

2. Gupta R. Meta-analysis of prevalence of hypertension in India. Indian Heart J. 1997 JanFeb;49(1):43-8.

3. Das SK, Sanyal K, Basu A. Study of urban community survey in India: growing trend of high prevalence of hypertension in a developing country. Int J Med Sci 2005; 2:70-78. doi:10.7150/ijms.2.70.
4. Kearney PM, Whelton M, Reynolds K, Muntner P, Whelton PK, He J. Global burden of hypertension: analysis of worldwide data. Lancet. 2005 Jan 1521;365(9455):217-23.

5. P Devi, M Rao, A Sigamani, A Faruqui, M Jose, R Gupta, P Kerkar, R K Jain, R Joshi, N Chidambaram, D S Rao, S Thanikachalam, S S Iyengar,K Verghese, V Mohan, P Pais and D Xavie . Prevalence, risk factors awareness of hypertension in India: a systematic review. Journal of Human Hypertension 2013; 27(5): 281 and 287.DOI: 10.1038/jhh.2012.33

6. Bharati DR, Nandi P, Yamuna TV, Lokeshmaran A, Agarwal L,Singh JB, Basu M, Das P,Pal. Prevalence and Covariates of Undiagnosed Hypertension in the Adult Population of Puducherry, South India. Nepal Journal of Epidemiology 2012; 2(2): 19199.DOI: http://dx.doi.org/10.3126/nje.v2i2.6576

7. Hypertension Study Group. Prevalence, awareness, treatment and control of hypertension among the elderly in Bangladesh and India: a multicentre study. Bull World Health Organ. 2001;79(6):490-500.

8. Chobanian AV, Bakris GL, Black HR, et al. National Heart, Lung, and Blood Institute Joint National Committee on Prevention, Detection, Evaluation, and Treatment of High Blood Pressure; National High Blood Pressure Education Program Coordinating Committee. The Seventh Report of the Joint National Committee on Prevention, Detection, Evaluation, and Treatment of High Blood Pressure: the JNC 7 report. JAMA. 2003 May 21;289(19):2560-72. Epub 2003 May 14.

9. Gascón JJ, Sánchez-Ortuño M, Llor B, Skidmore D, Saturno PJ; Treatment Compliance in Hypertension Study Group. Why hypertensive patients do not comply with the treatment: results from a qualitative study. Fam Pract. 2004 Apr;21(2):125-30.

10. Ramli1 A, Ahmad N, Paraidathathu T: Medication adherence among hypertensive patients of primary health clinics in Malaysia Patient Preference and Adherence 2012; 6: 613-622. doi: 10.2147/PPA.S34704

11. Afia F A Marfo, Frances T Owusu-Daaku, Mercy Opare Addo, Ibrahim I Saana. Ghanaian Hypertensive Patients Understanding of their Medicines and Life 
Style Modification for managing Hypertension. Int $\mathbf{J}$ Pharm Pharm Sci, Vol 6, Issue 4, 165-170.

12. George R, D Silva F, D Souza JL: Perceived Barriers and Effectiveness of Planned Teaching Programme on Life Style Modification Practices of Persons with Hypertension. A Study in Dakshina Kannada, Mangalore JKIMSU 2012 ; 1(2) :117-123

13. Vooradi S, Mateti UV. A systemic review on lifestyle interventions to reduce blood pressure. J Health Res Rev. 2016;3(1):1-5. DOI: 10.4103/23942010.173558

14. Kearney P.M., Whelton M., Reynolds K., Whelton PK. and He J., Worldwide Prevalence of Hypertension: a Systematic Review. J. Hypertens. 2004; 22(1): pp119. PMID:15106785

15. Connor M, Rheeder P, Bryer A, Meredith M, Beukes M, Dubb A, Fritz V. The South African stroke risk in general practice study. S Afr Med J. 2005 May;95(5):334-9.

16. Khatib $\mathrm{O} \quad \mathrm{M}$ and El-Guindy $\mathrm{M}$ S. Clinical Guidelines for Management of Hypertension, World Health Organization Regional Office for the Eastern Mediterranean, Metropole, Cairo. 2005; pp 48, 49.

17. Tam C.F, Nguyen L, Pea S, Hajyan K, Kevork S, Davis R, Poon G, Lew P. The Effects of Age, Gender, Obesity, Health Habits, and Vegetable Consumption Frequency on Hypertension in Elderly Chinese, Americans Nutrition Research; Journal of Education and Practice, 2014; 5(5): pp25: 31-43.

18. Wright J.D, Hughes J.B, Ostchega Y, Yoon S S, Nwankwo T. Mean Systolic and Diastolic Blood Pressure in Adults Aged 18 and Over in the United States, National Health Statistics Reports, 2011; 35: pp1-22,24. PMID:21485611

19. Al Wehedy A, Abd Elhameed SH, and Abd El Hameed D. Effect of Lifestyle Intervention Program on Controlling Hypertension among Older Adults, Journal of Education and Practice, 2014; 5(5): p 61.
20. Pires Cláudia Geovana da Silva, Mussi Fernanda Carneiro. Health beliefs regarding diet: a perspective of hypertensive black individuals. Rev. esc. enferm. USP [Internet]. 2012 June; 46( 3 ): 580-589. http://dx.doi.org/10.1590/S0080-62342012000300008.

21. Awotidebe T.O., Adedoyin R.A., Rasaq W.A., Adeyeye V.O., Mbada C.E., Akinola O.T. and Otwombe K.N, Knowledge, Attitude and Practice of Exercise for Blood Pressure Control: A cross-sectional Survey, Journal of Exercise Science and Physiotherapy, 2014; (10) 1: pp 1-10.

22. Seham A. Abd El-Hay, Samira E, El Mezayen. Knowledge and Perceptions Related to Hypertension, Lifestyle Behavior Modifications and Challenges That Facing Hypertensive Patients IOSR Journal of Nursing and Health Science (IOSR-JNHS) Volume 4, Issue 6 Ver. I (Nov. - Dec. 2015), PP 15-26 doi:10.9790/195904611526

23. Okwuonu C.G., Emmanuel C.I. and Ojimadu N.E., Perception and Practice of Lifestyle Modification in the Management of Hypertension among Hypertensive in South-East Nigeria, International Journal of Medicine and Biomedical Research, 2014; 3 (2): p 121-131.

24. Demaio AR, Dugee O, de Courten M, Bygbjerg IC, Enkhtuya P, Meyrowitsch DW. Exploring knowledge, attitudes, and practices related to alcohol in Mongolia: a national population-based survey. BMC Public Health. 2013 Feb 27;13:178. doi: 10.1186/1471-2458-13-178.

25. Shaikh RB, Mathew E, Sreedharan J, Muttappallymyalil J, Sharbatti SA, Basha SA. Knowledge regarding risk factors of hypertension among entry year students of a medical university. J Family Community Med. 2011 Sep;18(3):124-9. doi: 10.4103/2230-8229.90011.

26. Ali S., Sathiakumar N. and Delzell E., Prevalence and Socio-Demographic Dactors Associated with Tobacco Smoking among Adult Males in Rural Sindh, Pakistan, Southeast Asian J. Trop. Med. Public Health, 2006; (37): pp1054-60.

27. Jolles EP, Padwal, R.S. Clark, A.M.Braam. A Qualitative Study of Patient Perspectives about Hypertension[http://www.hindawi.com/isrn/hypertensio n/2013/671691/cta/] 
28. Chiazor IE, Oparah C A. Assessment of Hypertension Carein a Nigerian Hospital. Tropical Journal of Pharmaceutical Research 2012; 11 (1): 137145. http://dx.doi.org/10.4314/tjpr.v11i1.18

29. Kalra S, Kalra B, Agrawal N. Combination therapy in hypertension: An update. Diabetol Metab Syndr. 2010 Jun 24;2(1):44. doi: 10.1186/1758-5996-2-44.

30. Ni H, Nauman D, Burgess D, Wise K, Crispell K, Hershberger R. Factors Influencing Knowledge of and Adherence to Self Care among Patients With Heart
Failure. Arch. Intern. Med. 1999 ;159 (14)pp:16131619. PMID:10421285.

31. Li X, Ning N, Hao Y, Sun H, Gao L, Jiao M, Wu Q, Quan H. Health literacy in rural areas of China: hypertension knowledge survey. Int $\mathrm{J}$ Environ Res Public Health. 2013 Mar 18;10(3):1125-38. doi: 10.3390/ijerph10031125.

32. Azubuike S.O. and Kurmi R., Awareness, Practices, and Prevalence of Hypertension among Rural Nigerian Women, the Official Journal of Yenepoya University, 2014 ; (2) 1: pp 23-28. DOI: $10.4103 / 2321$ 4848.133791 .

\section{How to cite this article?}

Dhakal M., Dhakal O.P. A hospital based cross sectional study to evaluate awareness of lifestyle interventions among hypertensive patients in Sikkim (North-Eastern State of India). Int J Med Res Rev 2017;5(04):421-428. doi:10.17511/ijmrr. 2017.i04.08. 